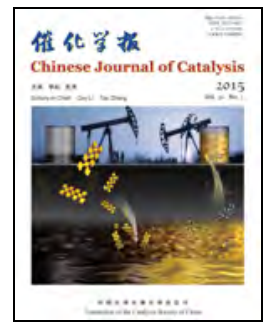

Article

\title{
Titania-supported Pt catalyst reduced with HCHO for HCHO oxidation under mild conditions
}

\author{
Huayao Chen a , Zebao Rui a,b, Hongbing Ji a a,b,* \\ a Department of Chemical Engineering, School of Chemistry \& Chemical Engineering, Sun Yat-Sen University, Guangzhou 510275, Guangdong, China \\ ${ }^{\mathrm{b}}$ R\&D Center of Waste-gas Cleaning \& Control, Huizhou Research Institute of Sun Yat-Sen University, Huizhou 516081, Guangdong, China
}

A R T I C L E I N F O

Article history:

Received 9 June 2014

Accepted 9 July 2014

Published 20 February 2015

Keywords:

Formaldehyde

Platinum

Titanium

In-situ diffuse reflectance infrared

Fourier transform spectroscopy

Deposition-precipitation

\begin{abstract}
A B S T R A C T
A series of $\mathrm{Pt} / \mathrm{TiO}_{2}(\mathrm{P} 25)$ catalysts were prepared by both impregnation (IM) and deposition-precipitation (DP) methods followed by reduction using either a $\mathrm{HCHO}$ solution or a $\mathrm{H}_{2}$ stream. The effects of the preparation and reduction conditions and the Pt loading level on structural properties and performance during $\mathrm{HCHO}$ oxidation were then studied based on the assessment of adsorbed species on the catalyst surfaces using in-situ diffuse reflectance infrared Fourier transform spectroscopy (DRIFTS). The results indicated that Pt/P25 prepared by DP and reduced with HCHO exhibited homogeneously dispersed Pt nanoparticles with appropriate particle size in addition to a high concentration of chemisorbed oxygen, and also showed high activity for HCHO oxidation. A HCHO conversion of $98 \%$ with stable performance over more than $100 \mathrm{~h}$ was achieved over Pt/P25 produced using DP and $\mathrm{HCHO}$ reduction at $30{ }^{\circ} \mathrm{C}$, even with a $0.4 \% \mathrm{Pt}$ loading. Pt/P25 synthesized using DP with $\mathrm{H}_{2}$ reduction was less effective at promoting formate decomposition and thus showed less HCHO oxidation activity, likely because of lower levels of chemisorbed oxygen. The Pt/P25 made using $\mathrm{IM}$ and $\mathrm{H}_{2}$ reduction had the highest amount of chemisorbed oxygen but also the largest Pt particles, resulting in the lowest activity for both the formation of formate species and formate decomposition into $\mathrm{CO}$ species, and thus showed low HCHO oxidation activity.
\end{abstract}

(c) 2015, Dalian Institute of Chemical Physics, Chinese Academy of Sciences. Published by Elsevier B.V. All rights reserved.

\section{Introduction}

Formaldehyde (HCHO) is one of the most common toxic volatile organic compounds; it is known to be carcinogenic and may cause leukemia [1]. Consequently, many methods have been proposed to remove trace levels of HCHO in air, including adsorption, photocatalysis, and catalytic oxidation [2]. Among these, catalytic oxidation is one of the most effective and economically feasible technologies because HCHO can be oxidized to $\mathrm{CO}_{2}$ over catalysts at much lower temperatures than those are required for thermal oxidation [3]. The catalytic decompo- sition of $\mathrm{HCHO}$ at room temperature is particularly desirable because of the attendant environmentally friendly reaction conditions. Recently, significant progress has been achieved with regard to decreasing the reaction temperature necessary for HCHO oxidation by employing Pt catalysts with various supports [4-11], especially when using titania-supported Pt catalysts.

Despite this success, $\mathrm{Pt} / \mathrm{TiO}_{2}$ materials are frequently reported to exhibit inconsistent activity for HCHO oxidation even when identical $\mathrm{Pt}$ loadings and $\mathrm{TiO}_{2}$ support structures are applied. As an example, Peng and Wang [7] reported that the

\footnotetext{
*Corresponding author. Tel: +86-20-84113658; Fax: +86-20-84113654; E-mail: jihb@mail.sysu.edu.cn

This work was supported by the National Natural Science Foundation of China (21106189 and 21036009), the Natural Science Foundation of Guangdong Province (S2011040001767), and the Fundamental Research Funds for the Central Universities (12lgpy11).

DOI: 10.1016/S1872-2067(14)60192-3 | http://www.sciencedirect.com/science/journal/18722067 | Chin. J. Catal., Vol. 36, No. 2, February 2015
} 
optimal Pt loading in a series of $\mathrm{Pt} / \mathrm{TiO}_{2}$ catalysts reduced in $\mathrm{H}_{2}$ at $450{ }^{\circ} \mathrm{C}$ was $0.6 \%$. The room temperature $\mathrm{HCHO}$ conversions obtained in their study were $0.8 \%, 1.0 \%$, and $41.5 \%$ over $0.01 \%, 0.1 \%$, and $0.6 \% \mathrm{Pt} / \mathrm{TiO}_{2}$, respectively, while the conversion obtained with $1 \% \mathrm{Pt} / \mathrm{TiO}_{2}$ dropped to $14.3 \%$, although this value increased to $97 \%$ at $120^{\circ} \mathrm{C}$. In contrast, Zhang and He [6] reported that $\mathrm{HCHO}$ could be completely oxidized into $\mathrm{CO}_{2}$ and $\mathrm{H}_{2} \mathrm{O}$ at room temperature over $\mathrm{Pt} / \mathrm{TiO}_{2}$ with a relatively high 1\% Pt loading level. Recently, Huang et al. [12] found that nearly $100 \%$ conversion of HCHO was achieved over sodium borohydride-reduced $\mathrm{Pt} / \mathrm{TiO}_{2}$ catalysts even with a low $\mathrm{Pt}$ loading of $0.1 \%$.

Differences in experimental parameters, such as the Pt loading method, the $\mathrm{TiO}_{2}$ support properties, and the reduction procedure, have been suggested to account for such discrepancies. Huang et al. [12] prepared a series of $\mathrm{Pt} / \mathrm{TiO}_{2}$ catalysts by the impregnation and deposition-precipitation method while applying different reduction processes and evaluated their activity for the catalytic decomposition of HCHO at room temperature. This study showed that the reduction treatment had a significant effect on the structural properties and HCHO oxidation activity of the $\mathrm{Pt} / \mathrm{TiO}_{2}$ catalysts. The authors concluded that well-dispersed and negatively charged metallic Pt nanoparticles together with high levels of chemisorbed oxygen were likely responsible for the high catalytic activity of the $\mathrm{NaBH}_{4}$-reduced $\mathrm{Pt} / \mathrm{TiO}_{2}$ catalysts. However, further study is still required to relate the catalyst preparation and reduction conditions to the structural properties of the catalyst, and to elucidate the detailed mechanism leading to the high catalytic activity and stability of these catalysts. Moreover, because some of the above catalysts were reduced in a $\mathrm{NaBH}_{4}$ solution, the finished materials may have contained residual $\mathrm{Na}$ and $\mathrm{B}$ [12], which could have had various effects on the performance of the catalysts. Zhang et al. [3] reported that the presence of $\mathrm{Na}^{+}$had a positive effect on the catalytic activity of $\mathrm{Pt} / \mathrm{TiO}_{2}$, to the extent that it changed the HCHO catalytic oxidation mechanism. Thus, in those catalysts contaminated with residual ions, it is difficult to ascertain which factors are actually affecting the performance of the catalyst. Recently, Qu et al. [13] reported that Ag/SBA-15 catalyst treated with a HCHO solution also showed high activity for HCHO oxidation. In comparison with $\mathrm{NaBH}_{4}$ solution reduction, reduction with $\mathrm{HCHO}$ solution leaves no additional elements on the treated catalyst, which provides an opportunity to study the effects of the reduction conditions on the structure, properties, and catalytic performance of the catalyst. To the best of our knowledge, the open literature contains very few reports focusing on the HCHO reduction process and its effects on the structure, properties, and catalytic performance of Pt-based catalysts.

The present paper reports the synthesis of a highly efficient $\mathrm{Pt} / \mathrm{TiO}_{2}$ catalyst intended for $\mathrm{HCHO}$ oxidation by a deposition-precipitation (DP) method followed by reduction via treatment with HCHO. A detailed study of the effects of the $\mathrm{Pt} / \mathrm{TiO}_{2}$ preparation and reduction conditions and the Pt loading amount on the structural properties and performance during trace $\mathrm{HCHO}$ oxidation is presented. The mechanism responsible for the high catalytic activity and stability of these materi- als is examined using in-situ diffuse reflectance infrared Fourier transform spectroscopy (DRIFTS), which represents a powerful technique for the investigation of surface species in real-world conditions $[6,14]$.

\section{Experimental}

\subsection{Catalyst preparation}

Two different Pt loading methods were used to prepare $\mathrm{Pt} / \mathrm{TiO}_{2}$ catalysts, the impregnation method and DP method, producing materials denoted as Pt/P25(IM) and Pt/P25(DP), respectively. The Pt/P25(IM) catalyst was prepared by uniformly dispersing $\mathrm{P} 25$ powder (Degauss) into a $\mathrm{H}_{2} \mathrm{PtCl}_{6}$ solution $\left(\mathrm{H}_{2} \mathrm{PtCl}_{6} \cdot 6 \mathrm{H}_{2} \mathrm{O}\right.$, Alfa Aesar) with the appropriate $\mathrm{H}_{2} \mathrm{PtCl}_{6}$ concentration. After vigorous stirring, the sample was washed with distilled water and centrifuged three times to remove any impurities on the surface of the catalyst. The catalyst was then dried overnight at $120{ }^{\circ} \mathrm{C}$ to evaporate the solvent. The Pt/P25(DP) catalysts were prepared by first dispersing the P25 support in deionized water, following which a $\mathrm{H}_{2} \mathrm{PtCl}_{6}$ solution was added dropwise into the P25 slurry with vigorous stirring at $70{ }^{\circ} \mathrm{C}$. After stirring for $1 \mathrm{~h}$, the $\mathrm{pH}$ of the solution was adjusted to 8 by adding an aqueous $\mathrm{NaOH}$ solution, and deposition by precipitation was allowed to continue for $2 \mathrm{~h}$ under vigorous stirring at $70{ }^{\circ} \mathrm{C}$. The catalyst was subsequently washed and centrifuged three times to remove any surface impurity, and the resulting powder was dried overnight at 120 ${ }^{\circ} \mathrm{C}$. Two different reduction methods were used when preparing catalysts, $\mathrm{H}_{2}$ reduction and $\mathrm{HCHO}$ solution reduction, producing specimens referred to as Pt/P25(IM- $\left.\mathrm{H}_{2}\right)$, Pt/P25(DP$\mathrm{H}_{2}$ ), and Pt/P25(DP-HCHO). During a typical $\mathrm{H}_{2}$ reduction process, the as-prepared Pt/P25(IM) or Pt/P25(DP) was calcined in a $\mathrm{H}_{2}$ stream $(40 \mathrm{ml} / \mathrm{min})$ at $300^{\circ} \mathrm{C}$ for $3 \mathrm{~h}$. Pt/P25(DP-HCHO) was prepared using a deposition-precipitation method similar to that described above, the only difference being that a HCHO solution (37\%-40\%, Guangzhou Reagent Company) was added to the DP solution after the $\mathrm{pH}$ of the solution was adjusted. Note that the Pt loading levels in this work are expressed as the mass percent of Pt in the catalyst, as confirmed by inductively coupled plasma (ICP, IRIS (HR)) elemental analysis.

\subsection{Catalyst characterization}

In-situ DRIFTS analyses were carried out using an EQVINOX-55 FFT instrument (Bruker) equipped with a diffuse reflectance accessory and an MCT detector. During each analysis, a finely ground sample (ca. $10 \mathrm{mg}$ ) was placed in a ceramic crucible within the in-situ chamber. A $100 \mathrm{ml} / \mathrm{min}$ flow of nitrogen gas containing $\mathrm{HCHO}$ was then passed through the chamber. Spectra under reaction conditions were recorded by averaging 64 scans with a resolution of $4 \mathrm{~cm}^{-1}$. Metal nanoparticle size distributions were observed using a JEOL 2100F transmission electron microscope (TEM), and the compositions of the samples were characterized by an energy-dispersive spectrometer fitted to a JEM-2010HR TEM. BET surface areas of the samples were determined by $\mathrm{N}_{2}$ adsorption at $-196{ }^{\circ} \mathrm{C}$ 
employing a Micromeritics ASAP 2020 instrument. Prior to these measurements, the samples were degassed at $300{ }^{\circ} \mathrm{C}$ for $2 \mathrm{~h}$. CO chemisorption was performed using a Micromeritics ASAP 2020C automated system. Prior to CO chemisorption, approximately $0.2 \mathrm{~g}$ of freshly calcined catalyst was evacuated to $1.33 \times 10^{-6} \mathrm{~Pa}$ at $110^{\circ} \mathrm{C}$ for $30 \mathrm{~min}$ and then reduced under a flow of $\mathrm{H}_{2}$ at $200^{\circ} \mathrm{C}$ for $30 \mathrm{~min}$. The catalyst was then evacuated again at $200{ }^{\circ} \mathrm{C}$ for 30 min to desorb any $\mathrm{H}_{2}$, and the chemisorption analysis was carried out at $35^{\circ} \mathrm{C}$. An average $\mathrm{CO} / \mathrm{Pt}$ stoichiometry of one was assumed for the dispersion calculations. X-ray photoelectron spectra (XPS) were recorded on a ESCALAB 250 spectrometer (Thermo Fisher Scientific, Al $K_{\alpha}, H v$ $=1486.6 \mathrm{eV}$ ) under a vacuum of approximately $2 \times 10^{-7} \mathrm{~Pa}$. Charging effects were corrected by adjusting the main $\mathrm{C} 1 \mathrm{~s}$ peak to a position of $284.8 \mathrm{eV}$.

\subsection{HCHO catalytic oxidation}

The catalytic oxidation of HCHO was performed in a quartz tube (i.d. $=7 \mathrm{~mm}$ ) fixed-bed reactor under atmospheric pressure using an apparatus constructed in-house. Approximately $0.2 \mathrm{~g}$ of the catalyst was packed into the reactor, and a simulated air stream $\left(\mathrm{N}_{2}\right.$ and $\mathrm{O}_{2}$ at 4 and $\left.100 \mathrm{ml} / \mathrm{min}\right)$ containing $\sim 50$ $\mathrm{mg} / \mathrm{m}^{3} \mathrm{HCHO}$ and water vapor ( $\sim 35 \%$ relative humidity) was introduced as the reactant stream. Gaseous HCHO was generated by passing a stream of the simulated air through a bubbler containing a $35 \%$ HCHO solution. The gas hourly space velocity (GHSV, defined as the total flow rate of gas at STP per unit mass of catalyst) in the test apparatus was $30000 \mathrm{ml} /(\mathrm{h} \cdot \mathrm{g})$. The HCHO concentration in the reactant and product gas streams was analyzed by a phenol spectrophotometric method. In this method, the gas stream containing trace levels of HCHO was bubbled through $5 \mathrm{ml}$ of a phenol reagent $\left(\mathrm{C}_{6} \mathrm{H}_{4} \mathrm{SN}\left(\mathrm{CH}_{3}\right) \mathrm{C}\right.$ : $\mathrm{NNH}_{2} \cdot \mathrm{HCl}$, Alfa Aesar) solution $\left(1 \times 10^{-6}\right)$ for $30 \mathrm{~s}$ to collect HCHO by absorption, following which $0.4 \mathrm{ml}$ of an ammonium ferric sulfate $\left(\mathrm{NH}_{4} \mathrm{Fe}\left(\mathrm{SO}_{4}\right)_{2} \cdot 12 \mathrm{H}_{2} \mathrm{O}, 1 \%\right.$, Tianjin Fuchen Chemical Reagent Company) solution was added as the coloring reagent. After shaking for $5 \mathrm{~s}$ and sitting for $15 \mathrm{~min}$ in the dark, the HCHO concentration was determined by measuring light absorbance at $630 \mathrm{~nm}$ with a spectrophotometer (UV-240, Shimadzu Co. Ltd., Japan). The conversion of HCHO was calculated based on the change in the concentration between the reactant and product gas streams.

\section{Results and discussion}

\subsection{Structural properties}

Because the Pt particles on the $0.4 \% \mathrm{Pt} / \mathrm{P} 25$ samples were too small to be detected by TEM, the TEM images and Pt particle size distributions of $0.8 \% \mathrm{Pt} / \mathrm{P} 25$ catalysts prepared by DP or IM followed by reduction with a $\mathrm{H}_{2}$ stream or a $\mathrm{HCHO}$ solution are compared in Fig. 1. It can be seen that small, homogeneous Pt nanoparticles were uniformly present on all the reduced catalysts. Approximately $500 \mathrm{Pt}$ nanoparticles were measured to obtain a histogram of the metal particle size distribution of each sample. In Fig. 1(b), a Pt nanoparticle size
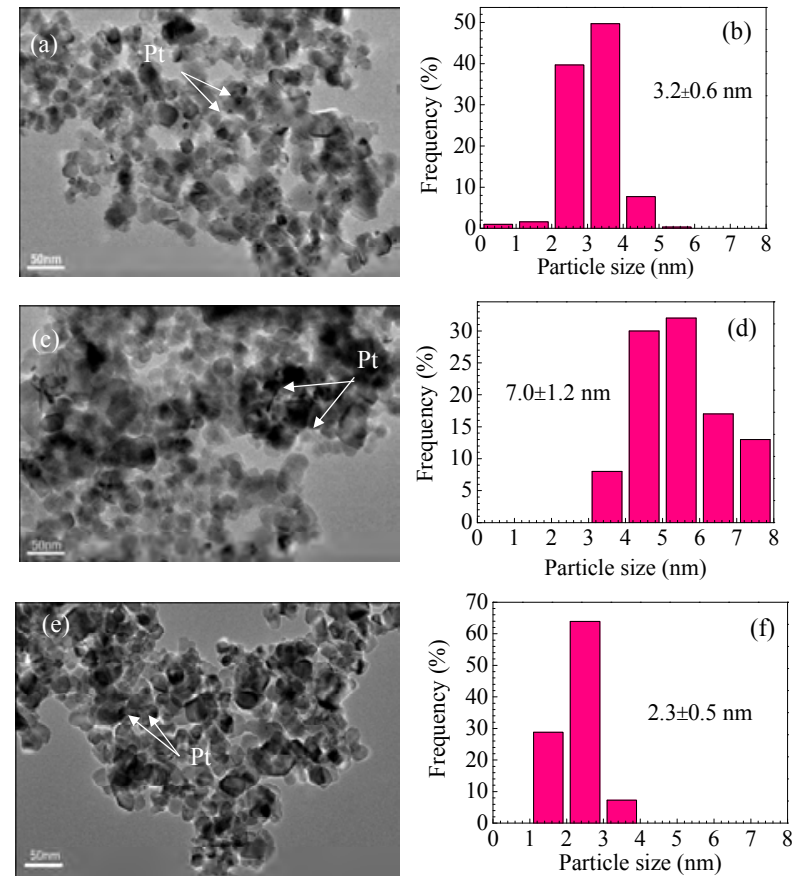

Fig. 1. TEM images and $\mathrm{Pt}$ nanoparticle size distributions of $0.8 \% \mathrm{Pt} / \mathrm{P} 25(\mathrm{DP}-\mathrm{HCHO})$ ((a) and (b)), 0.8\%Pt/P25(IM-H $)$ ((c) and (d), and $0.8 \% \mathrm{Pt} / \mathrm{P} 25\left(\mathrm{DP}-\mathrm{H}_{2}\right)((\mathrm{e})$ and $(\mathrm{f}))$.

range of 1-6 nm was observed in the case of the $0.8 \% \mathrm{Pt} / \mathrm{P} 25$ (DP-HCHO) sample, with an average value of $3.2 \mathrm{~nm}$; while a wider Pt nanoparticle size range of 3 to $8 \mathrm{~nm}$ with an average value of $7.0 \mathrm{~nm}$ was calculated for $0.8 \% \mathrm{Pt} / \mathrm{P} 25\left(\mathrm{IM}-\mathrm{H}_{2}\right)$, as presented in Fig. 1(d). Fig. 1(f) shows that the 0.8\%Pt/P25(DP-H ${ }_{2}$ had a size range of 1 to $4 \mathrm{~nm}$ with an average value of $2.3 \mathrm{~nm}$. The metal dispersions over the $0.4 \% \mathrm{Pt} / \mathrm{P} 25(\mathrm{DP}-\mathrm{HCHO}$ ) and $0.4 \% \mathrm{Pt} / \mathrm{P} 25\left(\mathrm{DP}-\mathrm{H}_{2}\right)$ specimens determined by $\mathrm{CO}$ chemisorption were $27.7 \%$ and $34.5 \%$, respectively, and their BET areas were 54.1 and $51.1 \mathrm{~m}^{2} / \mathrm{g}$, respectively. These results indicate that both the preparation method and the subsequent reduction process have significant effects on the surface Pt distribution and the catalyst structure but not on the support properties, which has a great influence on the catalytic activity [6].

\subsection{XPS results}

XPS analyses were carried out to identify the chemical states of surface elements, as shown in Fig. 2 and summarized in Table 1. Although the Pt $4 f$ signal was somewhat weak because of the low levels of Pt loading and its wide dispersion, the negative binding energy (BE) shift of Pt $4 f$ could still be observed at loadings over $0.4 \%$, giving the $70.2,70.3$, and $70.9 \mathrm{eV}$ values obtained for Pt/P25(DP-HCHO), Pt/P25(IM-H2), and Pt/P25 (DP-H $)$, respectively (Fig. 2(a)). These values may be compared with the BE of $71.2 \mathrm{eV}$ of bulk metallic Pt [15]. Electron transfer from $\mathrm{TiO}_{2}$ to the Pt core is believed to be responsible for this negative shift $[16,17]$. As can be seen in Fig. 2(b), the Ti $2 p$ peak was also shifted to a lower BE compared with the BE of $458.9 \mathrm{eV}$ previously reported for unreduced samples [12], suggesting the presence of oxygen vacancies $[18,19]$. Oxygen 

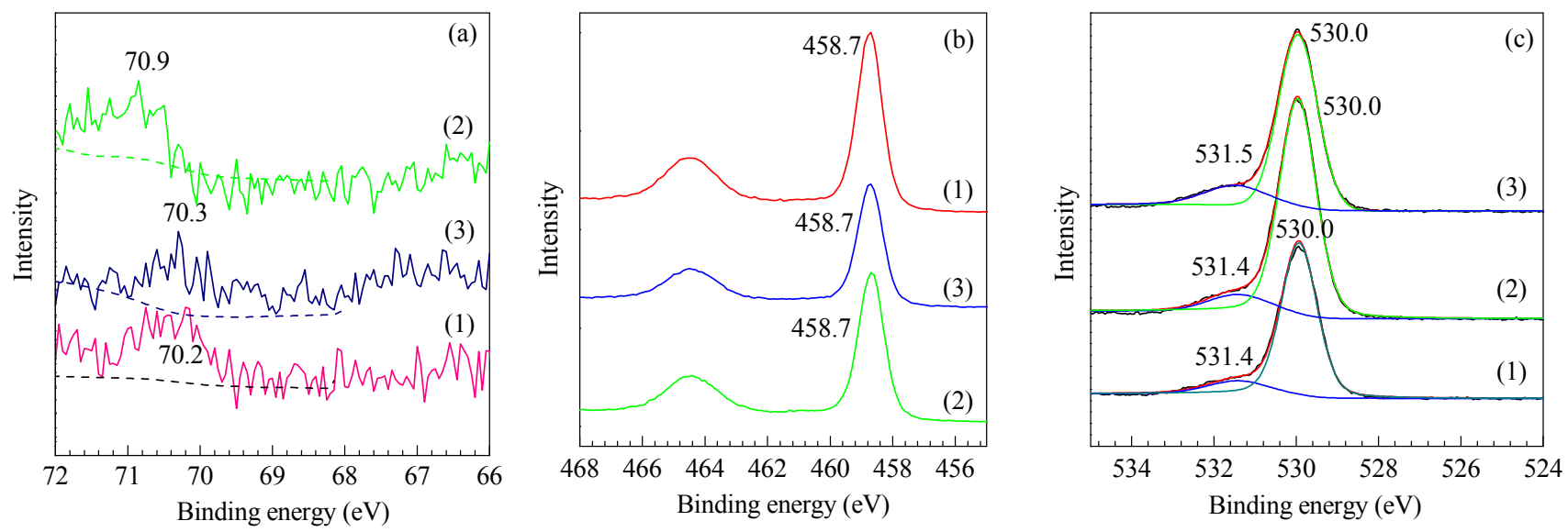

Fig. 2. XPS spectra of reduced $0.4 \% \mathrm{Pt} / \mathrm{P} 25$ catalysts. (a) Pt $4 f$; (b) Ti $2 p$; (c) 0 1s. (1) $0.4 \% \mathrm{Pt} / \mathrm{P} 25(\mathrm{DP}-\mathrm{HCHO}$ ); (2) 0.4\% Pt/P25(DP-H2); (3) $0.4 \% \mathrm{Pt} / \mathrm{P} 25\left(\mathrm{IM}-\mathrm{H}_{2}\right)$.

vacancies and negatively charged Pt particles both show enhanced capacity for $\mathrm{O}_{2}$ adsorption. A significant shoulder peak due to chemisorbed oxygen was present in the spectra of all the reduced Pt/P25 catalysts, as shown in Fig. 2(c). The amount of chemisorbed oxygen may be influenced by many factors, including the electronegativity and dispersion of the $\mathrm{Pt}$ and the presence of oxygen vacancies in the support [12,20-22]. It thus appears that both the preparation method and the reduction method have a significant effect on the surface Pt properties and chemisorbed oxygen concentrations, as listed in Table 1. The chemisorbed oxygen can be activated on the metal-support interface, forming highly active oxygen species that are involved in the oxidation reaction [23].

\subsection{Catalyst activity}

The catalytic activity of pure P25 and the Pt/P25 catalysts prepared using either the IM or DP methods followed by reduction with a $\mathrm{HCHO}$ solution or a $\mathrm{H}_{2}$ stream was evaluated for HCHO oxidation, with the results presented in Fig. 3(a). It is evident that the Pt/P25 catalysts prepared by the DP method were more active than those prepared using the IM method. In the case of the Pt/P25 materials prepared by the DP method, reduction with the $\mathrm{HCHO}$ solution was also more effective than the $\mathrm{H}_{2}$ stream reduction. The $0.4 \% \mathrm{Pt} / \mathrm{TiO}_{2}\left(\mathrm{IM}-\mathrm{H}_{2}\right)$ catalyst produced a $\mathrm{HCHO}$ conversion of $12.0 \%$ at $30^{\circ} \mathrm{C}$, and this value increased to $70.7 \%$ at $110{ }^{\circ} \mathrm{C}$. Even those samples with lower Pt loadings, $0.16 \% \mathrm{Pt} / \mathrm{TiO}_{2}\left(\mathrm{DP}-\mathrm{H}_{2}\right)$ and $0.16 \% \mathrm{Pt} / \mathrm{TiO}_{2}(\mathrm{DP}-\mathrm{HCHO})$, exhibited better activities, especially the $0.16 \% \mathrm{Pt} / \mathrm{TiO}_{2}$ (DP-

Table 1

XPS data obtained for reduced $0.4 \% \mathrm{Pt} / \mathrm{P} 25$ catalysts.

\begin{tabular}{|c|c|c|c|c|c|}
\hline \multirow[b]{2}{*}{ Sample } & \multicolumn{3}{|c|}{$\mathrm{BE}(\mathrm{eV})$} & \multicolumn{2}{|c|}{ Surface atom ratio ${ }^{a}$} \\
\hline & $\operatorname{Pt} 4 f_{7 / 2}$ & $\begin{array}{l}\mathrm{O}_{\text {adsorbed }} \\
\left(\mathrm{O}_{\text {lattice }}\right) \\
\end{array}$ & Ti $2 p$ & $\begin{array}{c}O_{\text {adsorbed }} \\
/ O_{\text {lattice }} \\
\end{array}$ & $\mathrm{Pt} / \mathrm{Ti}$ \\
\hline Pt/P25(DP-HCHO) & 70.2 & $531.4(530.0)$ & 458.7 & 0.14 & 0.0010 \\
\hline $\mathrm{Pt} / \mathrm{P} 25\left(\mathrm{DP}-\mathrm{H}_{2}\right)$ & 70.9 & $531.4(530.0)$ & 458.7 & 0.11 & 0.0015 \\
\hline $\mathrm{Pt} / \mathrm{P} 25\left(\mathrm{IM}-\mathrm{H}_{2}\right)$ & 70.3 & $531.5(530.0)$ & 458.7 & 0.20 & 0.0010 \\
\hline
\end{tabular}

a Calculated from the corresponding areas of fitted peaks using XPSPEAK 4.1 with a Shirley background.
HCHO). With increasing Pt loadings, the HCHO conversion reached a maximum of $\sim 98 \%$ over both $0.4 \% \mathrm{Pt} / \mathrm{TiO}_{2}\left(\mathrm{DP}-\mathrm{H}_{2}\right)$ and $0.4 \% \mathrm{Pt} / \mathrm{TiO}_{2}$ (DP-HCHO) even at room temperature, as shown in Fig. 3(b). These findings demonstrate that the preparation method and the reduction method both contribute to the activity of the catalysts.

Fig. 3(b) summarizes the results of long-term tests over
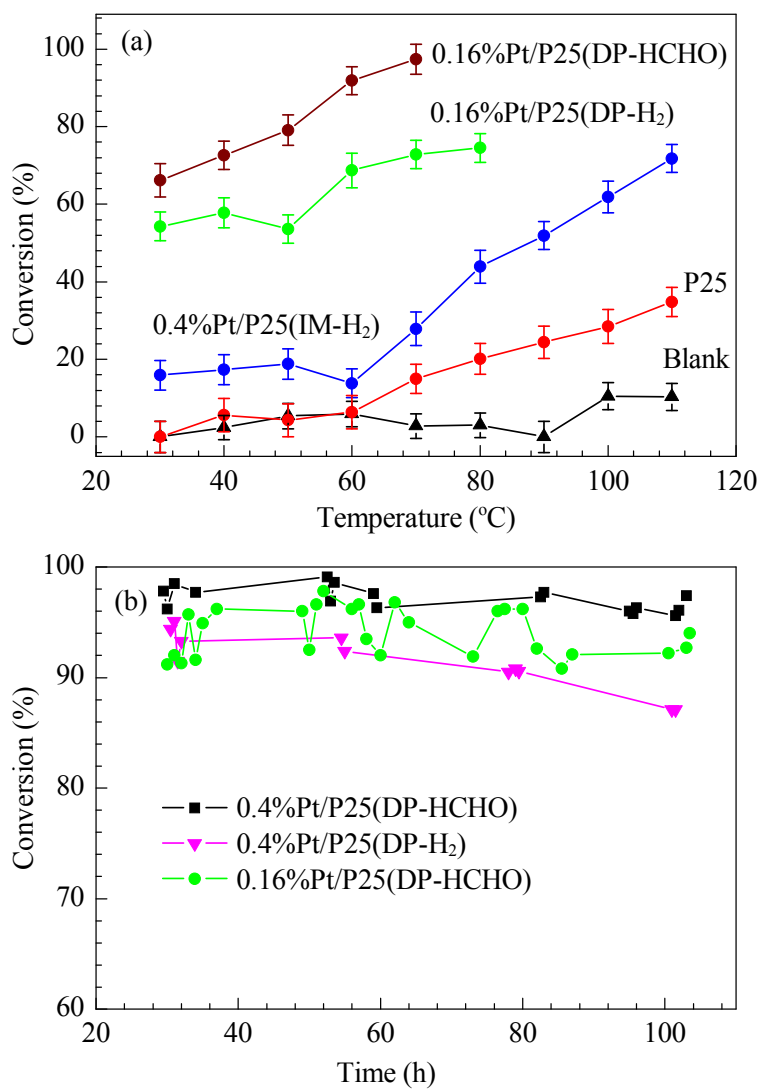

Fig. 3. (a) Dependence of $\mathrm{HCHO}$ conversion on reaction temperature for P25, 0.16\%Pt/P25(DP-HCHO), 0.16\%Pt/P25(DP- $\left.\mathrm{H}_{2}\right)$, and 0.4\%Pt/P25 $\left(\mathrm{IM}-\mathrm{H}_{2}\right)$ catalysts; (b) $\mathrm{HCHO}$ conversion over $0.4 \% \mathrm{Pt} / \mathrm{P} 25\left(\mathrm{DP}-\mathrm{H}_{2}\right)$ and $0.4 \% \mathrm{Pt} / \mathrm{P} 25$ (DP-HCHO) at $30{ }^{\circ} \mathrm{C}$ and $0.16 \% \mathrm{Pt} / \mathrm{P} 25$ (DP-HCHO) at $70{ }^{\circ} \mathrm{C}$ over prolonged time periods. 
$0.4 \% \mathrm{Pt} / \mathrm{P} 25\left(\mathrm{DP}-\mathrm{H}_{2}\right)$ and $0.4 \% \mathrm{Pt} / \mathrm{P} 25(\mathrm{DP}-\mathrm{HCHO})$ at $30{ }^{\circ} \mathrm{C}$ and $0.16 \% \mathrm{Pt} / \mathrm{P} 25$ (DP-HCHO) at $70^{\circ} \mathrm{C}$. As shown, the $0.4 \% \mathrm{Pt} / \mathrm{P} 25$ (DP-HCHO) shows good stability over the $100 \mathrm{~h}$ test with a HCHO conversion of around 98\%, while $0.16 \%$ Pt/P25(DP$\mathrm{HCHO}$ ) also presents good stability with a HCHO conversion of approximately 94\%. The HCHO conversion over 0.4\%Pt/P25 (DP- $\left.\mathrm{H}_{2}\right)$, however, decreases rapidly from $94 \%$ to $87 \%$ during the long-term on-stream test.

\subsection{In-situ DRIFT analyses}

In the following experimental trials, the differing activities of Pt/P25 catalysts prepared and activated with different methods were studied during $\mathrm{HCHO}$ oxidation with respect to the behavior of adsorbed species on the catalyst surface, using in-situ DRIFTS. Fig. 4 presents the dynamic changes in the DRIFTS spectra of the $0.4 \% \mathrm{Pt} / \mathrm{P} 25$ catalysts as a function of time in a flow of $\mathrm{O}_{2}+\mathrm{HCHO}+\mathrm{He}$ at $30{ }^{\circ} \mathrm{C}$. After exposing the catalyst to the $\mathrm{O}_{2}+\mathrm{HCHO}+\mathrm{He}$ mixture, four bands appeared at $2062,1657,1570$, and $1359 \mathrm{~cm}^{-1}$. According to previous studies, the two strong bands at 1570 and $1359 \mathrm{~cm}^{-1}$ are ascribed to $v_{\text {as }}(\mathrm{COO})$ and $v_{s}(\mathrm{COO})$ on catalyst sites $[24,25]$, demonstrating that the adsorbed $\mathrm{HCHO}$ was converted into formate species. The very weak band at $2062 \mathrm{~cm}^{-1}$ is assignable to linear CO adsorbed on Pt [6], and the band at $1657 \mathrm{~cm}^{-1}$ is due to water adsorbed on the catalyst (originating from the water in the
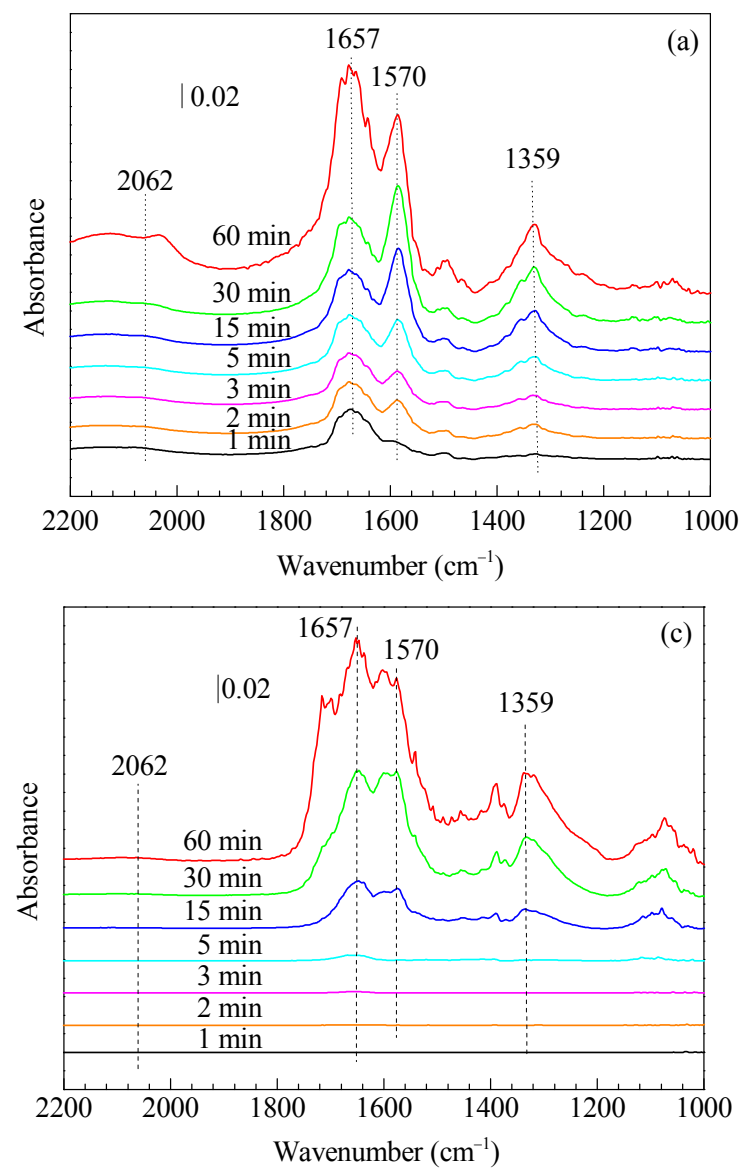

reactant gas mixture) [6]. In our previous work [26], we found that adsorbed formate species and adsorbed CO were the main intermediate species, based on in-situ DRIFTS analysis. With increasing exposing time, the band intensities increase and reach a steady level after $60 \mathrm{~min}$. A semi-quantitative analysis was performed by calculating the integrated area of the formate species band at $1570 \mathrm{~cm}^{-1}$, and the results showed that, during the first 5 min of on-stream time, both the band intensities and the intensity increment over the Pt/P25(DP-HCHO) were the largest among these samples, while with increasing time both the band intensities and the intensity increment over $\mathrm{Pt} / \mathrm{P} 25\left(\mathrm{DP}-\mathrm{H}_{2}\right)$ became the largest, and Pt/P25(IM-H2) exhibited the smallest values during the entire $60 \mathrm{~min}$ on-stream time. The amount of formate species over the catalyst surface is determined by two factors: the formation rate from adsorbed $\mathrm{HCHO}$ and the decomposition rate. The overall effect of the two factors can increase or decrease the formate species amount, depending on their relative dominance. Based on these results in combination with the activity test data provided in Fig. 3, we propose that the lower formate species amount over the $\mathrm{Pt} / \mathrm{P} 25\left(\mathrm{IM}-\mathrm{H}_{2}\right)$ is due to the slow formation of formate species on this material. Both the formate species formation rate and decomposition rate over the Pt/P25(DP-HCHO) are the fastest, resulting in a lower concentration of formate species but higher activity in comparison with the activity obtained over the Pt/P25(DP-H2).
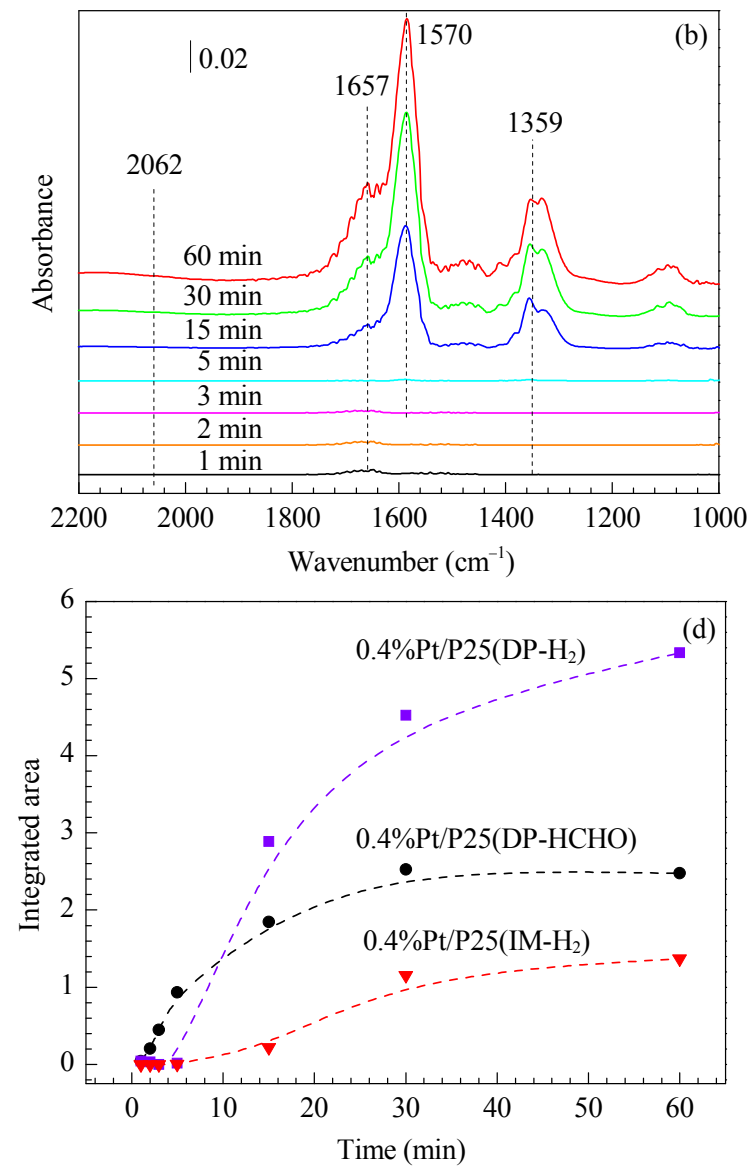

Fig. 4. In-situ DRIFTS spectra of $\mathrm{O}_{2}+\mathrm{HCHO}+\mathrm{He}$ gas mixture adsorption over (a) $0.4 \% \mathrm{Pt} / \mathrm{P} 25(\mathrm{DP}-\mathrm{HCHO}),\left(\right.$ b) $0.4 \% \mathrm{Pt} / \mathrm{P} 25\left(\mathrm{DP}-\mathrm{H}_{2}\right)$, and (c) $0.4 \% \mathrm{Pt} / \mathrm{P} 25\left(\mathrm{IM}-\mathrm{H}_{2}\right)$ at $30^{\circ} \mathrm{C}$ and $(\mathrm{d})$ areas of $1570 \mathrm{~cm}^{-1}$ peak over time for these same materials. 

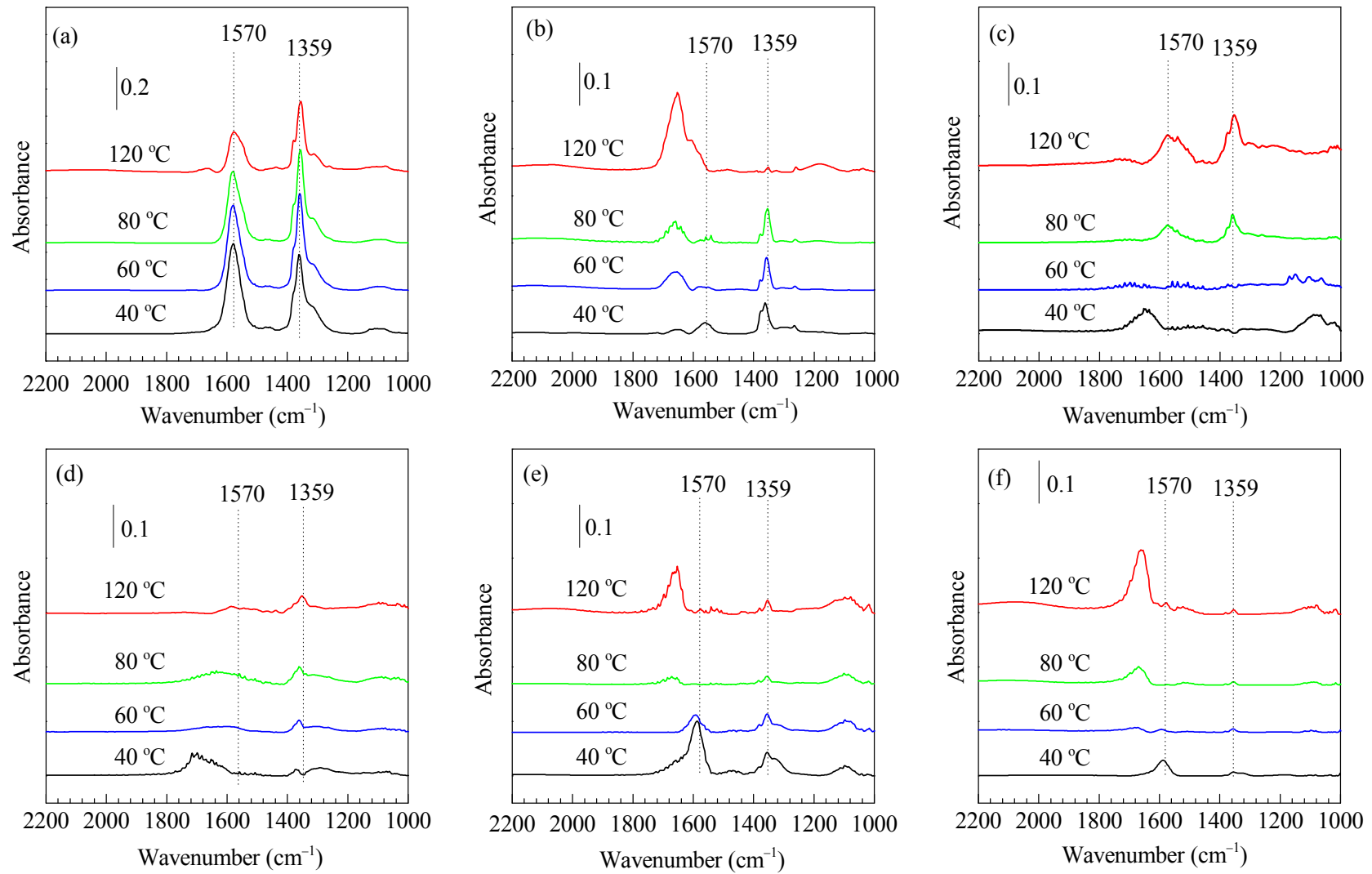

Fig. 5. In-situ DRIFTS spectra of $\mathrm{O}_{2}+\mathrm{HCHO}+\mathrm{He}$ gas mixture adsorption at various temperatures over (a) 0.16\% $\mathrm{Pt} / \mathrm{P} 25$ (DP-HCHO), (b)

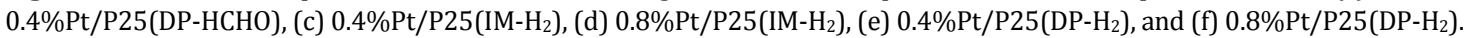

Fig. 5 summarizes the changes in the DRIFTS spectra of the Pt/P25 catalysts made with different Pt loading amounts and different activation methods at various temperatures in a flow of $\mathrm{O}_{2}+\mathrm{HCHO}+\mathrm{He}$. As shown, the band ascribed to the adsorbed formate species at $1570 \mathrm{~cm}^{-1}$ varied with both temperature and Pt loading amount for all the samples.

Fig. 6 shows changes in band intensity with temperature and Pt loading amounts. For the Pt/P25(DP-HCHO), the band intensity decreased with increasing temperature and Pt loading, and a similar trend is also observed over Pt/P25(DP-H2), as shown in Fig. 6(b). Over Pt/P25(IM-H $)$, however, the band intensity increased with increasing temperature and Pt loading. A comparison of the intensity changes over Pt/P25(DP-HCHO), $\mathrm{Pt} / \mathrm{P} 25\left(\mathrm{DP}-\mathrm{H}_{2}\right)$, and Pt/P25(IM- $\left.\mathrm{H}_{2}\right)$, all with the same $0.4 \% \mathrm{Pt}$ loading, is presented in Fig. 6(d). It is apparent that both the band intensity and the change of intensity with temperature over Pt/P25(DP-H $)$ were the largest. These results are consistent with the activity test results in Fig. 3 and the dynamic changes in the DRIFTS spectra in Fig. 4. Pt/P25(DP-HCHO) was thus active with regard to both the fast conversion of adsorbed HCHO to formate species and the oxidation of formate species even at room temperature. Therefore, with the exception of the $0.16 \% \mathrm{Pt} / \mathrm{P} 25$ (DP-HCHO), although a relatively high concentration of adsorbed formate species was detected, high activity for the oxidation reaction was observed over the Pt/P25(DP$\mathrm{HCHO}$ ) catalysts. In the case of the Pt/P25(IM- $\left.\mathrm{H}_{2}\right)$ materials, the low concentration of adsorbed formate species together with reduced activity during the oxidation reaction indicates that the generation of formate species is also a necessary step in the HCHO oxidation process, especially at a low reaction temperatures and reduced $\mathrm{Pt}$ loadings. With increasing $\mathrm{Pt}$ loading amounts or elevated reaction temperatures, the accumulation of adsorbed formate species over the Pt/P25 $\left(\mathrm{IM}-\mathrm{H}_{2}\right)$ catalysts indicates that the enhanced oxidation of formate species became the rate-determining step. The activity of the $\mathrm{Pt} / \mathrm{P} 25\left(\mathrm{DP}-\mathrm{H}_{2}\right)$ was between those of the Pt/P25(DP-HCHO) and $\mathrm{Pt} / \mathrm{P} 25\left(\mathrm{IM}-\mathrm{H}_{2}\right)$. The rapid generation of formate species over Pt/P25(DP-H $)_{2}$ materials can evidently be realized even at room temperature. However, the rate of formate species oxidation over Pt/P25(DP-H2) was lower than that over Pt/P25(DP-HCHO), and the accumulated formate species would therefore tend to block the active areas [25], resulting in lower HCHO oxidation activity. The results also indicate that the rate-determining step during $\mathrm{HCHO}$ oxidation over the $0.4 \% \mathrm{Pt} / \mathrm{P} 25\left(\mathrm{DP}-\mathrm{H}_{2}\right)$ was the complete oxidation of formate species. With increasing Pt loadings or elevated reaction temperatures, the concentration of adsorbed formate species decreased while the activity rapidly increased.

Zhang and He [6] proposed a reaction scheme for HCHO oxidation over $\mathrm{TiO}_{2}$-supported noble metal catalysts involving the behavior of surface-adsorbed species, based on data obtained from in-situ DRIFTS. In this mechanism, HCHO is initially oxidized into formate surface species (step 1), following which the formate surface species decompose directly to produce ad- 

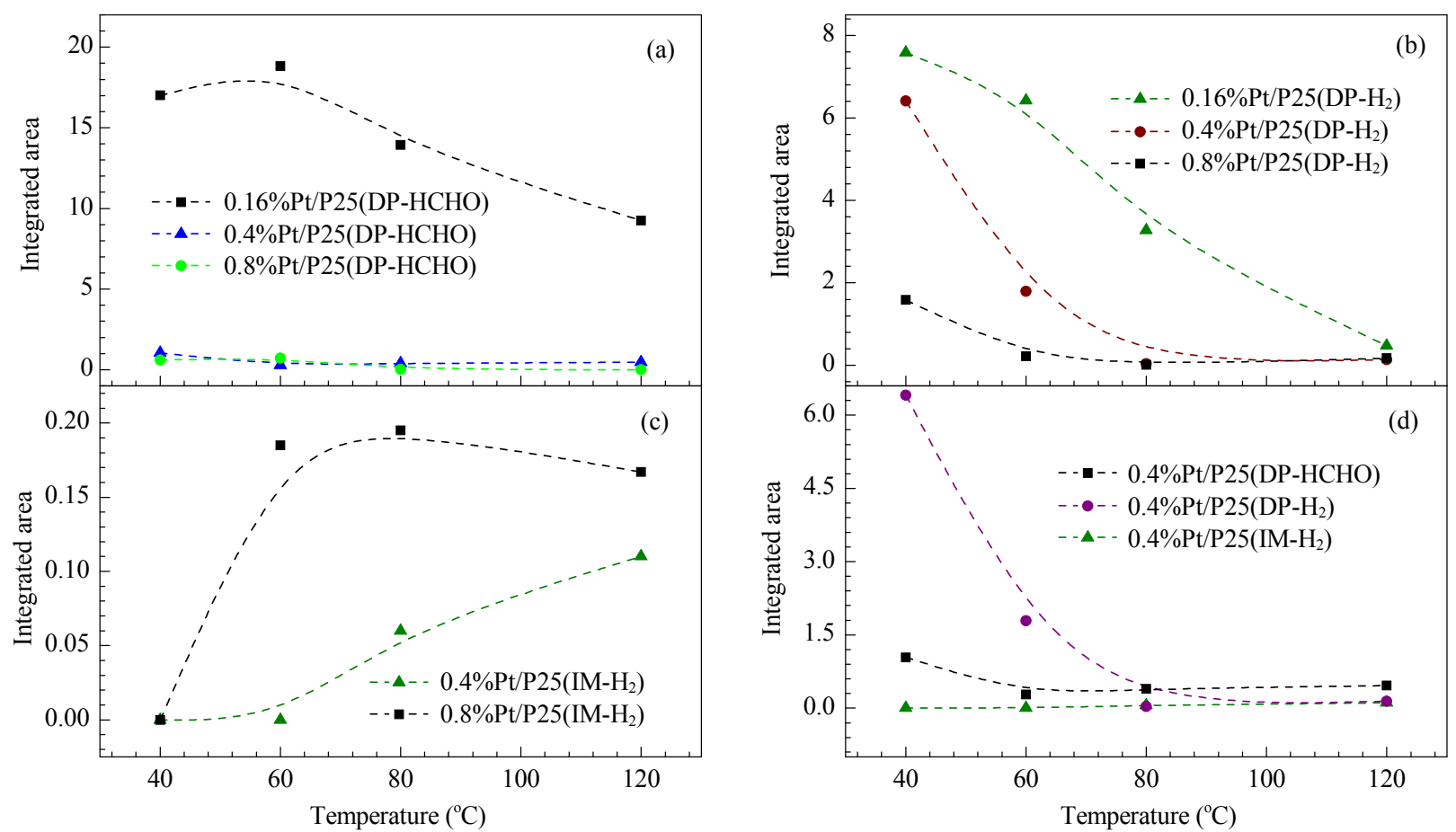

Fig. 6. Intensity of the $1570 \mathrm{~cm}^{-1}$ band as a function of temperature for (a) Pt/P25(DP-HCHO), (b) Pt/P25(DP- $\mathrm{H}_{2}$ ), and (c) Pt/P25(IM- $\mathrm{H}_{2}$ ) at various Pt loadings and (d) a comparison of these groups of catalysts.

sorbed $\mathrm{CO}$ species and $\mathrm{H}_{2} \mathrm{O}$ (step 2) and, finally, these CO species react with $\mathrm{O}_{2}$ to produce gas phase $\mathrm{CO}_{2}$ (step 3). The conversion of surface formate species to adsorbed $\mathrm{CO}$ on the catalysts (step 2) is usually regarded as the rate-determining step for $\mathrm{Pt} / \mathrm{TiO}_{2}$ catalysts $[6,13]$. Based on the in-situ DRIFTS data from our recent work [20], however, we generally separated this process into two parts: a storage step and an oxidation step. In the storage step, HCHO is initially chemisorbed and reacts with chemisorbed oxygen to generate formate surface species and then decomposes into adsorbed $\mathrm{CO}$ species and $\mathrm{H}_{2} \mathrm{O}$. In the oxidation step, the adsorbed $\mathrm{CO}$ species react with $\mathrm{O}_{2}$ or chemisorbed oxygen to produce gas phase $\mathrm{CO}_{2}$, and gaseous $\mathrm{O}_{2}$ is reactivated by the active sites to form chemisorbed oxygen. In the present study, we determined that both the Pt loading method and the reduction treatment have significant effects on the structural properties of the Pt/P25 catalysts and the resulting catalytic activity for HCHO oxidation, such that uniformly dispersed metallic Pt nanoparticles with smaller size were obtained on the Pt/P25(DP) compared with the Pt/P25(IM). Although the relatively large Pt particles resulted in greater quantities of chemisorbed oxygen over the $\mathrm{Pt} / \mathrm{P} 25\left(\mathrm{IM}-\mathrm{H}_{2}\right)$, which is considered an important factor with regard to instilling high activity in the reduced $\mathrm{Pt} / \mathrm{TiO}_{2}$ catalysts [12], the Pt/P25(IM-H2) still exhibited lower catalytic activity. A semi-quantitative analysis based on the in-situ DRIFTS study indicated that the Pt/P25(IM- $\left.\mathrm{H}_{2}\right)$ was much less effective for either the formation of formate species or formate decomposition, and so the activity of these materials for HCHO oxidation was very low. Although both Pt/P25(DP-HCHO) and $\mathrm{Pt} / \mathrm{P} 25\left(\mathrm{DP}-\mathrm{H}_{2}\right)$ were prepared with the same Pt loading method, the average Pt particle size, chemisorbed oxygen concentra- tion, and HCHO oxidation activity over the Pt/P25(DP-HCHO) were all greater than those over the Pt/P25(DP-H2), indicating that the reduction treatment had a pronounced influence on the structural properties and catalytic activity of the Pt/P25 catalysts. The in-situ DRIFTS data indicated that the Pt/P25(DP- $\left.H_{2}\right)$ was less effective with regard to formate decomposition, and so its activity for $\mathrm{HCHO}$ oxidation was lower than that of the Pt/P25(DP-HCHO). All these results indicate that the presence of metallic Pt with an appropriate particle size in conjunction with an optimal concentration of chemisorbed oxygen leads to much more efficient HCHO oxidation. The site density of reactive surface oxygen, which is considered an important factor in the activity of $\mathrm{Pt} / \mathrm{TiO}_{2}$ catalysts [12], increases with larger Pt particles [21,27] such that overly small $\mathrm{Pt}$ particles (such as on the Pt/P25(DP- $\mathrm{H}_{2}$ ) in this work) lead to poor activity, especially in the conversion of surface-adsorbed formate species. However, the overall activity of Pt/P25 diminishes with further increases in the Pt particle size because of the activity loss caused by the simultaneous decrease in the number of surface Pt atoms. Thus, although the Pt/P25(IM- $\left.\mathrm{H}_{2}\right)$ had a high concentration of chemisorbed oxygen, it was less effective for HCHO oxidation.

\section{Conclusions}

We have demonstrated that both the Pt loading method and the reduction treatment have significant effects on the structural properties of the Pt/P25 catalysts, as well as the resulting catalytic activity for $\mathrm{HCHO}$ oxidation. Pt/P25 catalysts prepared by the DP method followed by HCHO reduction showed homogenously dispersed Pt nanoparticles of appropriate size, as 


\title{
Graphical Abstract
}

Chin. J. Catal., 2015, 36: 188-196 doi: 10.1016/S1872-2067(14)60192-3

\section{Titania-supported Pt catalyst reduced with HCHO for HCHO oxidation under mild conditions}

Huayao Chen, Zebao Rui, Hongbing Ji* Sun Yat-Sen University

$\mathrm{A} \mathrm{Pt} / \mathrm{TiO}_{2}(\mathrm{P} 25)$ catalyst was prepared by deposition-precipitation (DP) and reduction with HCHO. The catalyst exhibited homogenously dispersed, appropriately sized Pt particles and a high concentration of chemisorbed oxygen and showed high activity for HCHO oxidation.

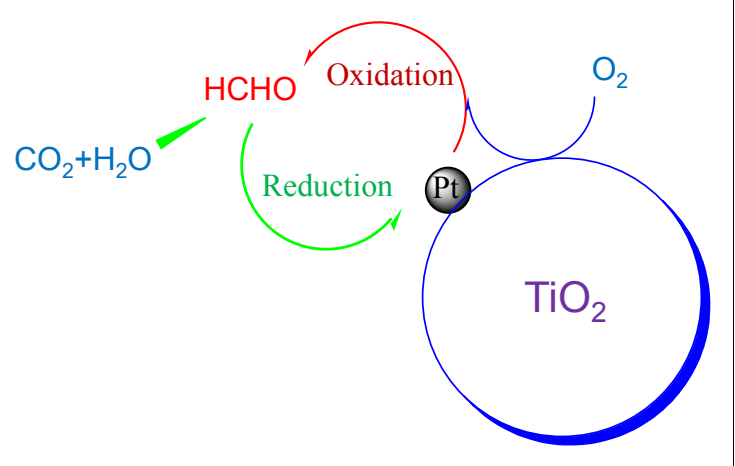

2008, 81: 115

well as high concentrations of chemisorbed oxygen and high activity for $\mathrm{HCHO}$ oxidation. A HCHO conversion of $98 \%$ was achieved over the Pt/P25(DP-HCHO) at $30{ }^{\circ} \mathrm{C}$ even at a relatively low Pt loading of $0.4 \%$, and this conversion was stable for more than $100 \mathrm{~h}$. Pt/P25 prepared by the DP method but reduced with $\mathrm{a} \mathrm{H}_{2}$ stream was less effective in terms of the formate decomposition step and thus exhibited lower rates of HCHO oxidation, likely because of low levels of chemisorbed oxygen. Pt/P25 prepared by the IM method followed by reduction in $\mathrm{a}_{2}$ stream had the highest concentration of chemisorbed oxygen but the largest Pt particles, and thus showed the poorest activity for both the formation of formate species and the formate decomposition into $\mathrm{CO}$ species, and finally for HCHO oxidation. The activity barrier for HCHO oxidation over Pt/P25(DP-H 2$)$ and Pt/P25(IM-H2) can evidently be overcome by increasing both the $\mathrm{Pt}$ loading amount and the reaction temperature. In addition, the technique of reduction via a HCHO solution has been demonstrated to represent an effective means of reducing supported metal catalysts without introducing inorganic impurities.

\section{References}

[1] Bianchi F, Careri M, Musci M, Mangia A. Food Chem, 2007, 100: 1049

[2] Zhang M L, An T C, Fu J M, Sheng G Y, Wang X M, Hu X H, Ding X J. Chemosphere, 2006, 64: 423

[3] Zhang C B, Liu F D, Zhai Y P, Ariga H, Yi N, Liu Y C, Asakura K, Flytzani-Stephanopoulos M, He H, Angew Chem Int Ed, 2012, 51: 9628

[4] Tang X F, Chen J L, Huang X M, Xu Y D, Shen W J. Appl Catal B,
[5] Zhang C B, He H, Tanaka K-i. Appl Catal B, 2006, 65: 37

[6] Zhang C B, He H. Catal Today, 2007, 126: 345

[7] Peng J X, Wang S D. Appl Catal B, 2007, 73: 282

[8] Wang R H, Li J H. Catal Lett, 2009, 131: 500

[9] An N H, Yu Q S, Liu G, Li S Y, Jia M J, Zhang W X. J Hazard Mater, 2011, 186: 1392

[10] An N H, Zhang W L, Yuan X L, Pan B, Liu G, Jia M J, Yan W F, Zhang WX. Chem Eng J, 2013, 215-216: 1

[11] Park S J, Bae I, Nam I S, Cho B K, Jung S M, Lee J H. Chem Eng J, 2012, 195-196: 392

[12] Huang H B, Leung D Y C, Ye D Q. J Mater Chem, 2011, 21: 9647

[13] Qu Z P, Shen S J, Chen D, Wang Y.J Mol Catal A, 2012, 356: 171

[14] He Y B, Rui Z B, Ji H B. Catal Commun, 2011, 14: 77

[15] Schierbaum K D, Fischer S, Torquemada M C, de Segovia J L, Roman E, Martin-Gago J A. Surf Sci, 1996, 345: 261

[16] Aramendia M A, Colmenares J C, Marinas A, Marinas J M, Moreno J M, Navio J A, Urbano F J. Catal Today, 2007, 128: 235

[17] Alexeev O S, Chin S Y, Engelhard M H, Ortiz-Soto L, Amiridis M D. J Phys Chem B, 2005, 109: 23430

[18] Rengaraj S, Li X Z.J Mol Catal A, 2006, 243: 60

[19] Chen X Q, Liu H B, Gu G B. Mater Chem Phys, 2005, 91: 317

[20] Chen H Y, Rui Z B, Ji H B. Ind Eng Chem Res, 2014, 53: 7629

[21] Rui Z B, Wu S R, Peng C, Ji H B. Chem Eng J, 2014, 243: 254

[22] Zeng L, Song W L, Li M H, Zeng D W, Xie C S. Appl Catal B, 2014, 147: 490

[23] van Bokhoven J A, Louis C, Miller J T, Tromp M, Safonova O V, Glatzel P. Angew Chem Int Ed, 2006, 45: 4651

[24] Rasko J, Kecskes T, Kiss J. J Catal, 2004, 224: 261

[25] Kecskes T, Rasko J, Kiss J. Appl Catal A, 2004, 273: 55

[26] He Y B, Ji H B. Chin J Catal (何运兵, 纪红兵. 催化学报), 2010, 31: 171

[27] Garetto T F, Apesteguía C R. Appl Catal B, 2001, 32: 83

\section{甲醛还原 $\mathrm{Pt} / \mathrm{TiO}_{2}$ 催化剂用于温和条件下高效催化氧化甲醛}

\author{
陈铧耀, 芮泽宝 ${ }^{\mathrm{a}, \mathrm{b}}$, 纪红兵 ${ }^{\mathrm{a}, \mathrm{b}}{ }^{*}$ \\ ${ }^{a}$ 中山大学化学与化学工程学院化工系, 广东广州 510275

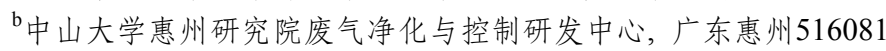


位红外监测催化剂表面吸附物种在反应过程中的变化, 探究了催化剂制备和还原条件及Pt负载量对催化剂结构和催化氧化甲醛 活性的影响. 结果显示, 用DP法制备并用甲醛还原的 Pt/P25催化剂中Pt颗粒分散均匀, 并具有合适的粒径和高浓度的表面活性氧, 显示出良好的甲醛氧化活性. 在空速 $30000 \mathrm{ml} /\left(\mathrm{g} \cdot \mathrm{h}\right.$ )、反应温度 $30^{\circ} \mathrm{C}$ 和甲醛初始浓度 $50 \mathrm{mg} / \mathrm{m}^{3}$ 的条件下, $0.4 \% \mathrm{Pt} / \mathrm{P} 25$ (DP-HCHO) 上的甲醛转化率达到 $98 \%$, 并能稳定运行 $100 \mathrm{~h}$ 以上. 相比之下, $\mathrm{Pt} / \mathrm{P} 25\left(\mathrm{DP}-\mathrm{H}_{2}\right)$ 由于表面活性氧较少, 不利于甲酸盐氧化, 活性较低. $\mathrm{Pt} / \mathrm{P} 25\left(\mathrm{IM}-\mathrm{H}_{2}\right)$ 虽然具有高浓度的表面活性氧, 却同时具有最大的Pt颗粒粒径, 在甲醛转化为甲酸盐和甲酸盐氧化两步反应中的活 性均较差, 因而甲醛氧化活性最差.

关键词: 甲醛; 铂; 二氧化钛; 原位红外光谱; 沉积-沉淀法

收稿日期: 2014-06-09; 接受日期: 2014-07-09. 出版日期: 2015-02-20.

*通讯联系人. 电话: (020)84113658; 传真: (020)84113654; 电子信箱: jihb@mail.sysu.edu.cn

基金来源：国家自然科学基金(21106189，21036009); 广东省自然科学基金(S2011040001767); 中央高校基本科研业务费专项资 金(12lgpy11).

本文的英文电子版由Elsevier出版社在ScienceDirect上出版(http://www.sciencedirect.com/science/journal/18722067).

\section{ScholarOne投审稿系统在《催化学报》正式上线}

为加速国际化进程, 《催化学报》于近日正式采用国际通用的SholarOne投审稿系统. 该系统使稿件管理更 加规范化和国际化, 更符合国际投稿和审稿习惯.

即日起《催化学报》原投审稿系统的用户名和密码将停止使用. 请作者和审稿专家访问本刊新投审稿网址: https://mc03.manuscriptcentral.com/chinjcatal, 通过您的E-mail在新系统上重新注册, 并获得新的用户名和密码 后即可使用.

感谢您一直以来对《催化学报》的关心和支持!

期刊详细信息请访问 http://www.chxb.cn 或http://www.elsevier.com/locate/chnjc

\section{Chinese Journal of Catalysis adopts online peer review system ScholarOne Manuscripts}

The Chinese Journal of Catalysis has recently adopted the ScholarOne Manuscripts system to manage the submissions and peer review process. This comprehensive online platform will further help promote academic exchange by streamlining the editorial and publication process: authors can enjoy ease of submission and can track manuscript review status while editors can manage review tasks in a dynamic, fully-integrated interface that enables the most informed decision-making. The ScholarOne Manuscript system was already launched on December 12, 2014, and all manuscripts should now be submitted online at https://mc03.manuscriptcentral.com/chinjcatal.

The user ID and password of the old system has already expired. Please register to login the ScholarOne Manuscripts using your e-mail address.

Thank you for your cooperation and kind support.

Websites: http://www.chxb.cn/EN/volumn/current.shtml http://www.elsevier.com/locate/chnjc 